RUTTER, M. (1987) Temperament, personality and personality disorder. British Journal of Psychiatry, 150, 443-458.

Stevenson, J. E. \& GrahaM, P. J. (1982) Temperament: a consideration of concepts and methods. In Temperamental Differences in Infants and Young Children. Ciba Foundation Symposium 89 (eds R. Porter and G. M. Collins). London: Pitman.

\section{Huntington's Chorea}

SIR: Martindale (Journal, March 1987, 150, 319-323) has raised an important issue that is relevant not only to Huntington's chorea but also to child psychiatry. It is well known that parents often have difficulty in recognising depression in their children. Professional responses to child psychiatric difficulties are less often discussed, and it seems worth drawing attention to a suggestion recently put forward by Emde $e t$ al (1986). Childhood depression was described many years ago, but it took a long time to gain general acceptance both by clinicians and by research workers. Emde et al hypothesised that this might be because depressed children threaten to arouse painful feelings in the professionals with whom they come into contact, and this may lead the professionals to fail to recognise the condition.

We are all familiar with 'observer effects' in research and these often seem to be regarded as contaminations which prevent us from discerning the truth. Both Martindale and Emde et al seem to suggest that this is only partially true and that some emotional responses (such as denial) will blind us to the truth, but others, such as the ability to tolerate feelings of hopelessness, helplessness and sadness in ourselves, may enable us to make a diagnosis which would otherwise elude us.

If this is correct it would seem to have several implications. Firstly, regarding teaching, perhaps we should spend more time helping our trainees to be more aware of their emotional responses to their patients; and secondly, as regards research, it would at least seem worth recording the emotional reactions of the interviewer to the patient.

My clinical impression is that patients often evoke similar emotional responses in a large number of professionals, and it could be that we should be taking more notice of this.

Department of Child and Family Psychiatry St Thomas' Hospital, London SE1 7EH

\section{Roference}

Emde, R. N., Harman, R. J. \& GoOd, W. V. (1986) Depressive feelings in children: a transactional model for research. In Depression in Young People, Developmental and Clinical Perspectives (eds M. Rutter, C. E. Izard and P. B. Read). New York \& London: The Guilford Press.

\section{Anorexia and Antidepressants}

SIR: We wish to take up and extend Crisp's theme (Journal, March 1987, 150, 355-358) regarding the mode of action of antidepressant drugs in patients with anorexia nervosa. We have recently studied a group of four male patients with eating disorder, depressive symptoms, and obsessional behaviour.

All four have several features in common, including early age of onset (13-15 years), dietary restriction with consequent weight loss, and obsessional, repetitive exercise routines. One patient exercises with such force that he has sustained several muscle injuries. Three of the patients have been admitted to hospital in the past with transient weight gain. All patients have experienced marked anxiety in relation to loss of control of body weight. This has occurred, for example, when exercise was disrupted by injury or infection, and has led to anticipatory ruminations about the risk of contracting illness and losing control over body weight or body 'fat content'.

In all four, obsessional behaviour has extended beyond the spheres of diet, preparation of food, and preoccupation with exercise to the extent that they are unable to make simple decisions-almost amounting to 'folie de doute'. Three of the four patients are high-achievers academically, pursuing courses in tertiary education; the fourth has been sufficiently ill to interrupt his schooling, although he was regarded premorbidly as being of above average potential. Their academic success has been jeopardised by their obsessional insistence on studying every subject in excessive detail, which leads to their falling behind in their study schedules, causing anxiety and precipitating further ruminations.

All four are currently improved in their academic and social functioning (but not in their core anorexic psychopathology) following the administration of drugs which block 5HT re-uptake with varying degrees of specificity (e.g. fluvoxamine or clomipramine).

Crisp justifies the use of clomipramine by drawing attention to the possible primary phobic and secondary avoidance behaviour and obsessional features within anorexia nervosa. We concur with the view that in some anorexic patients obsessional features play an important role (Dally, 1969), particularly in male patients (Beumont, 1972), and such symptoms contributed significantly to the difficulties encountered by our patients. Taking Crisp's argument that tricyclic drugs have an immediate effect on drive behaviour further, we suggest that in addition they reduce repetitive, 'stereotyped' behaviour as manifested in impaired decision-making seen in these patients. 